\title{
Systemic Oxidative Stress is Associated With Visceral Fat Accumulation and the Metabolic Syndrome
}

\author{
Koichi Fujita, MD; Hitoshi Nishizawa, MD; Tohru Funahashi, MD; \\ Iichiro Shimomura, MD; Michio Shimabukuro, MD*
}

\begin{abstract}
Background The metabolic syndrome (MetS) is a major target for prevention of atherosclerotic cardiovascular diseases and visceral fat accumulation is an underlying component of MetS. The aim of this study was to investigate the association of systemic oxidative stress with visceral fat accumulation and MetS.

Methods and Results The study group consisted of Japanese men $(n=44 ; 51.2 \pm 11.4$ years) and women $(n=61$; $55.4 \pm 13.4$ years). Urinary 8-epi-prostaglandin F2a (8-epi-PGF2a) concentration, a biomarker of systemic oxidative stress, was significantly high in the subjects with MetS. As the urinary concentration of 8-epi-PGF2a increased, the number of criteria for MetS were significantly met (abdominal obesity, hypertriglyceridemia, low high-density lipoprotein-cholesterol, hypertension, and high fasting glucose). Among parameters associated with MetS, the correlation coefficient of visceral fat area (VFA) with urinary 8-epi-PGF2a concentration was the highest $(r=0.636, p<0.0001)$. In non-obese subjects, the correlation coefficient of VFA with urinary 8-epi-PGF2a concentration was higher $(\mathrm{r}=0.728, \mathrm{p}<0.0001)$, although there was no significant correlation between subcutaneous fat area and urinary 8-epi-PGF2a. Stepwise multiple regression analysis identified VFA as the strongest and independent determinant of urinary 8-epi-PGF2a $(\mathrm{p}<0.0001)$ followed by adiponectin $(\mathrm{p}=0.0212)$ and, high sensitive C-reactive protein $(\mathrm{p}=0.0365)$.
\end{abstract}

Conclusions Systemic oxidative stress, as measured by urinary 8-epi-PGF2a, is strongly associated with visceral fat accumulation and MetS. (Circ J 2006; 70: 1437-1442)

Key Words: Metabolic syndrome; Systemic oxidative stress; Urinary 8-epi-PGF2a; Visceral fat accumulation

$\mathbf{T}$ he metabolic syndrome (MetS), a cluster of glucose intolerance, hypertension, and dyslipidemia with visceral fat accumulation, is a common health problem in industrialized countries and its management is a major target for the prevention of atherosclerotic cardiovascular diseases! ${ }^{-4}$ There is evidence for the role of obesity, particularly abdominal or intra-abdominal visceral fat accumulation, in promoting the development of metabolic diseases including glucose intolerance, dyslipidemia, hypertension, and atherosclerosis-5-9 Adipose tissue was previously considered an energy-storage organ, but numerous studies have demonstrated recently that adipose tissue produces and secretes a variety of biologically active molecules, conceptualized as adipocytokines, $, 4,10-14$ such as plasminogen activator inhibitor-1 (PAI-1) ${ }_{10}^{10}$ tumor necrosis factor (TNF)a ${ }^{11}$ resistin, 2 leptin ${ }^{13}$ and adiponectin ${ }^{14}$ Importantly, dysregulated production of adipocytokines in obesity is involved in the development of MetS!,4,10-15 Increased production of

(Received May 29, 2006; revised manuscript received July 31, 2006; accepted September 4, 2006)

Department of Metabolic Medicine, Graduate School of Medicine, Osaka University, Suita, *Second Department of Internal Medicine, Faculty of Medicine, University of the Ryukyus, Okinawa, Japan

Mailing address: Hitoshi Nishizawa, MD, Department of Metabolic Medicine, Graduate School of Medicine, Osaka University, 2-2-B5 Yamadaoka, Suita 565-0871, Japan. E-mail: hitoshin@imed2.med. osaka-u.ac.jp or Michio Shimabukuro, MD, Second Department of Internal Medicine, Faculty of Medicine, University of the Ryukyus, 207 Uehara, Nishihara, Okinawa 903-0215, Japan. E-mail: me447945 @ members.interq.or.jp
PAI-1 and TNFa from accumulated fat causes thrombosis, and atherosclerosis, respectively!10,16,17 Adiponectin exhibits anti-atherogenic ${ }^{18-20}$ and insulin-sensitizing properties ${ }^{21,22}$ Hypoadiponectinemia, associated with visceral fat area (VFA), is considered to play an important role in the development of coronary artery disease and type 2 diabetes in MetS?3-25

Oxidative stress has been implicated in the pathogenesis of atherosclerosis ${ }^{26-30}$ Reactive oxygen species (ROS) resulting from NADPH oxidase activation in cardiovascular cells are involved in the adhesion and migration of monocyte/macrophages, proliferation of vascular smooth muscle cells and fibroblasts, and remodeling of the extracellular matrix, leading to atherosclerotic cardiovascular diseases ${ }^{26}$ Recently, our group demonstrated that, in obese mice, production of ROS increased selectively in accumulated fat but not in muscle, liver, and aorta. The increase in fat ROS was associated with augmented expression of NADPH oxidase and decreased expression of antioxidative enzymes such as $\mathrm{Cu}, \mathrm{Zn}$-superoxide dismutase and catalase in adipose tissue ${ }^{31}$ These results suggest that obesity per se can induce systemic ROS. The same study also demonstrated that fat ROS can trigger the dysregulation of adipocytokines, such as decreased adiponectin and increased PAI-1 and TNFa, which would lead to the development of MetS. Treatment with NADPH oxidase inhibitor ameliorated adipocytokine dysregulation and improved the metabolic disorders. Therefore, fat ROS are considered a suitable therapeutic target and a biomarker for MetS. However, the association between systemic ROS and fat distribution, especially visceral fat 
Table 1 Clinical Characteristics of the Study Subjects

\begin{tabular}{|c|c|c|c|}
\hline & $\begin{array}{c}\operatorname{MetS}(-) \\
(n=69)\end{array}$ & $\begin{array}{c}\operatorname{MetS}(+) \\
(n=36)\end{array}$ & $p$ value \\
\hline Age (years) & $53.3 \pm 13.7$ & $54.2 \pm 10.6$ & $N S$ \\
\hline$B M I\left(\mathrm{~kg} / \mathrm{m}^{2}\right)$ & $25.8 \pm 5.0$ & $28.7 \pm 3.9$ & 0.0034 \\
\hline Waist circumference $(\mathrm{cm})$ & $91.0 \pm 13.1$ & $96.9 \pm 6.6$ & 0.0128 \\
\hline$V F A\left(\mathrm{~cm}^{2}\right)$ & $115.6 \pm 71.6$ & $183.7 \pm 94.6$ & 0.0012 \\
\hline $\operatorname{SFA}\left(\mathrm{cm}^{2}\right)$ & $171.2 \pm 94.0$ & $200.9 \pm 87.8$ & $N S$ \\
\hline Systolic blood pressure $(\mathrm{mmHg})$ & $124.5 \pm 15.7$ & $144.0 \pm 21.2$ & $<0.0001$ \\
\hline Diastolic blood pressure $(\mathrm{mmHg})$ & $71.2 \pm 11.0$ & $84.5 \pm 9.9$ & $<0.0001$ \\
\hline Total cholesterol $(\mathrm{mmol} / \mathrm{L})$ & $5.21 \pm 0.94$ & $5.90 \pm 1.04$ & 0.0009 \\
\hline Triglyceride $(\mathrm{mmol} / \mathrm{L})$ & $1.36 \pm 0.81$ & $2.58 \pm 1.40$ & $<0.0001$ \\
\hline HDL-cholesterol $(\mathrm{mmol} / \mathrm{L})$ & $1.49 \pm 0.41$ & $1.30 \pm 0.28$ & 0.0147 \\
\hline Fasting plasma glucose $(\mathrm{mmol} / \mathrm{L})$ & $5.67 \pm 1.52$ & $6.98 \pm 1.57$ & $<0.0001$ \\
\hline Hemoglobin Alc (\%) & $5.58 \pm 0.94$ & $6.41 \pm 1.19$ & 0.0002 \\
\hline Adiponectin $(\mu \mathrm{g} / \mathrm{ml})$ & $6.73 \pm 3.31$ & $5.11 \pm 2.20$ & 0.0263 \\
\hline$h s C R P(m g / L)$ & $1.80 \pm 3.13$ & $3.11 \pm 3.77$ & 0.0017 \\
\hline Smoking (\%) & 15 & 11 & $N S$ \\
\hline Urinary 8-epi-PGF2a $(\mathrm{pg} / \mathrm{mg} \mathrm{Cr})$ & $234.9 \pm 134.7$ & $309.4 \pm 112.3$ & 0.0054 \\
\hline
\end{tabular}

Data are mean $\pm S D$.

MetS, metabolic syndrome (Japanese criteria); NS, not significant; BMI, body mass index; VFA, visceral fat area; SFA, subcutaneous fat area; HDL, high-density lipoprotein; hsCRP, high-sensitive C-reactive protein; 8-epi-PGF2a, 8-epi-prostaglandin F2a.

accumulation, which plays a key role in MetS, has not been defined in human subjects.

In the present study, we investigated the correlations between systemic oxidative stress, measured by urinary 8epi-PGF2a concentration, and various conditions associated with MetS.

\section{Methods}

\section{Subjects}

Among 261 Japanese adults who visited the university hospital for a health checkup between 2003 and 2005, 105 [44 men (mean age \pm SD, $51.2 \pm 11.4$ years) and 61 women (55.4 \pm 13.4 years)] were recruited into the study. Subjects were excluded if they did not agree to participate, had a history of diabetes mellitus, cardiovascular or cerebrovascular disease, hepatic and/or renal disease, or were being treated with antihypertensive or antihyperlipidemic medications. Interested participants visited our laboratories by self-referral or by recommendation for further check-up after local center screening. The study protocol complied with the Guidelines of the Ethical Committees of Osaka University and University of the Ryukyus. Informed consent was given by all subjects.

\section{Anthropometry and Abdominal Fat Distribution}

Anthropometric measurements (height, weight and waist circumference (WC)) were performed in a standing position. Body mass index (BMI) was calculated as weight divided by the square of height $\left(\mathrm{kg} / \mathrm{m}^{2}\right)$. WC at the umbilical level was measured with a non-stretchable tape in the late exhalation phase while standing?22 Systolic and diastolic blood pressures were measured in the sitting position to the nearest $\mathrm{mmHg}$. Abdominal fat distribution was determined using computed tomography (CT) while the subjects were supine ${ }^{33}$ Ordinary CT parameters were used, specifically $120 \mathrm{kV}$ and $200 \mathrm{~mA}$, as well as a slice thickness of $5 \mathrm{~mm}$, a scanning time of $2 \mathrm{~s}$, and a field of view of $400 \mathrm{~mm}$. The subcutaneous fat area (SFA) and intra-abdominal VFA were measured at the level of the umbilicus and determined by a standardized method with CT numbers. Briefly, a region of interest of the subcutaneous fat layer was defined by tracing its contour on each scan, and the attenuation range of CT numbers (in Hounsfield units) for fat tissue was calculated. A histogram for fat tissue was computed on the basis of mean attenuation \pm 2 SD. Total and intraperitoneal tissue with attenuation within the mean $\pm 2 \mathrm{SD}$ were considered to be the total fat area (TFA) and VFA, and the SFA was defined by subtracting the VFA from the TFA. Smoking was assessed using a smoking index, defined cigarettes/day $\times$ years.

\section{Laboratory Measurements}

Blood was drawn after an overnight fast and plasma concentrations of adiponectin were measured by a sandwich enzyme-linked immunosorbent assay (ELISA) system (Adiponectin ELISA Kit, Otsuka Pharmaceutical Co, Tokushima, Japan) $!^{15}$ Plasma glucose concentrations were determined by glucose oxidase method. The value of hemoglobin A1c (HbA1c) was determined by high-performance liquid chromatography. Serum total cholesterol and triglyceride concentrations were determined by enzymatic methods. High-density lipoprotein (HDL)-cholesterol was also measured by enzymatic method after heparin and calcium precipitation. Serum concentration of C-reactive protein (CRP) was measured with high-sensitive CRP (hsCRP) assay (Denka Seiken). A single urine sample was subjected to analysis of systemic oxidative stress using urinary 8-epiprostaglandin F2a (8-epi-PGF2a) as the marker ${ }^{34}$ in an enzyme immunoassay kit (Assay Design Inc), as described previously $31,35,36$ The urinary concentration of 8-epi-PGF2a was indexed to that of urinary creatinine $(\mathrm{Cr})$ and expressed in $\mathrm{pg} / \mathrm{mg} \mathrm{Cr}$.

\section{Definition of MetS}

MetS was defined according to the 2005 guidelines of the Japanese Society of Internal Medicine or to the American Heart Association/National Heart, Lung, and Blood Institute (AHA/NHLBI) criteria?,38 In the Japanese guideline, which is similar to the IDF criteria 39,40 subjects with MetS must have: abdominal obesity (defined as $\mathrm{WC} \geq 85 \mathrm{~cm}$ in men or $\geq 90 \mathrm{~cm}$ in women ${ }^{41}$ ), and plus any 2 of the following 3 factors: (1) dyslipidemia: hypertriglyceridemia (serum triglyceride concentration $\geq 150 \mathrm{mg} / \mathrm{dl}[1.69 \mathrm{mmol} / \mathrm{L}]$ ) and $/$ or low HDL-cholesterol (serum concentration $<40 \mathrm{mg} / \mathrm{dl}$ 
a

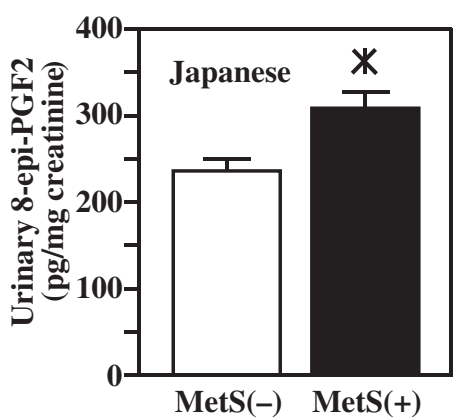

b

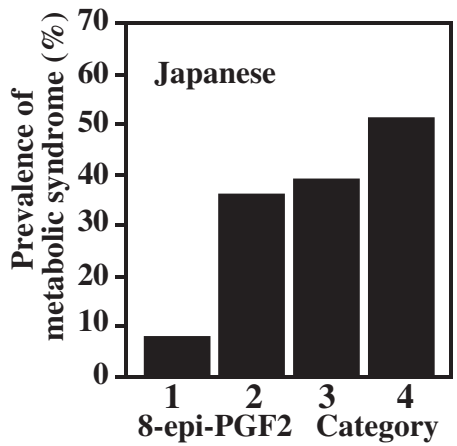

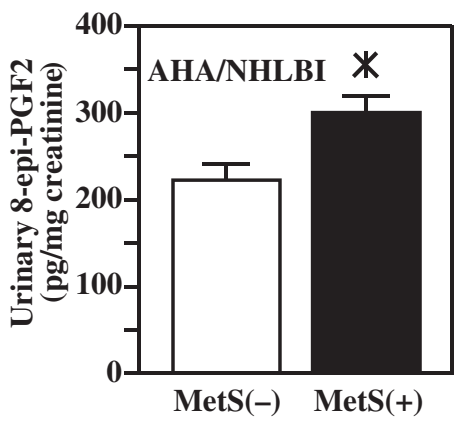

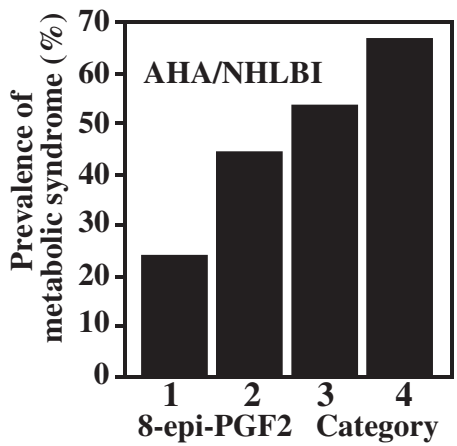

c

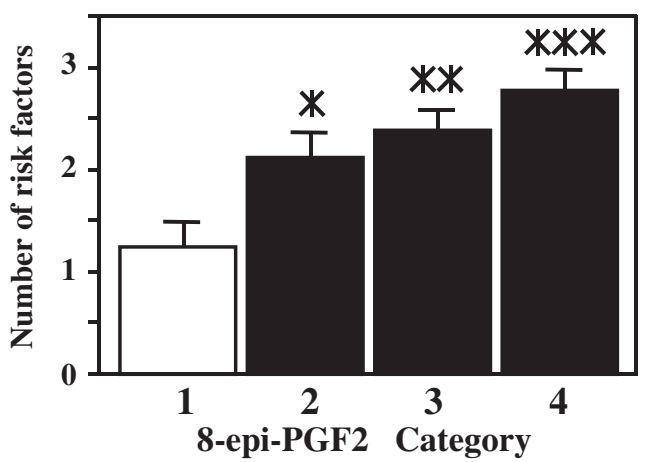

[1.04 mmol/L]); (2) hypertension: systolic blood pressure $\geq 130 \mathrm{mmHg}$ and/or diastolic blood pressure $\geq 85 \mathrm{mmHg}$; (3) high fasting glucose: serum glucose concentration $\geq 110 \mathrm{mg} / \mathrm{dl}(6.1 \mathrm{mmol} / \mathrm{L})$. In the present study, abdominal obesity was defined WC $\geq 85 \mathrm{~cm}$ in men or $\geq 90 \mathrm{~cm}$ in women as reported for Japanese population. ${ }^{41}$

\section{Statistical Analysis}

All statistical analyses were performed with Stat View-J 5.0 (Statistical Analysis System Inc, Cary, NC, USA). Because plasma adiponectin concentrations, hsCRP, and serum triglyceride concentrations did not show a Gaussian distribution, these 3 parameters were log-transformed before analysis. We compared clinical characteristics in the subjects with or without MetS (Table 1) using the Student's t-test. Only the prevalence of smokers was analyzed by the chi-square test. The subjects were then categorized into 4 groups according to the urinary concentrations of 8-epiPGF2a. The prevalence of the MetS in each category was analyzed by Mann-Whitney U-test. Comparisons of the mean values of components of the MetS in each category were analyzed by the Kruskal-Wallis test and Scheffe's test. Pearson's correlation coefficient was used to examine the association between urinary 8-epi-PGF2a concentration and various parameters of MetS. To identify the parameters of

Fig 1. Urinary 8-epi-prostaglandin F2a (8-epi-PGF2a) concentration and metabolic syndrome (MetS). (a) Urinary 8-epi-PGF2a concentrations in subjects with or without MetS. (Left panel) MetS (-): n=69, MetS $(+)$ : $n=36$, diagnosed by the Japanese criteria; (Right panel) MetS (-): $n=55$, MetS $(+): n=50$, diagnosed by the American Heart Association/National Heart, Lung, and Blood Institute (AHA/NHLBI) criteria. Data are mean \pm SEM. ${ }^{*} \mathrm{p}<0.01$ by Student's t-test. (b) Prevalence of MetS according to the category of urinary 8 -epi-PGF2a concentration (see text for details). Analysis using the Japanese criteria (Left panel) or the AHA/NHLBI criteria (Right panel). (c) The number of components of MetS (abdominal obesity, hypertriglyceridemia, low high-density lipoprotein-cholesterol, hypertension, and high fasting glucose) in each category of urinary 8-epi-PGF2a concentration. Data are mean \pm SEM. $* \mathrm{p}<0.05, * * \mathrm{p}<0.01, * * * \mathrm{p}<0.001$ vs category 1 by Kruskal-Wallis test and Scheffe's test.
MetS that contribute significantly to urinary 8-epi-PGF2a concentration, stepwise multiple regression analysis was conducted. Parameters with an F-value $>4.0$ were entered into the regression analysis as independent variables. A p-value less than 0.05 denoted a statistically significant difference.

\section{Results}

The basic anthropometric and metabolic characteristics of the subjects enrolled in this study are presented in Table 1. Based on the Japanese criteria, 34\% had MetS (Table 1, $40 \%$ of the enrolled men and $29 \%$ of the enrolled women), whereas according to the AHA/NHLBI criteria, $47 \%$ of the enrolled subjects had MetS (52\% of men and $44 \%$ of women). As expected, between the subjects with and without MetS according to Japanese criteria, there were significant differences in several parameters related to MetS, including BMI, WC, VFA, systolic and diastolic blood pressures, total cholesterol, triglyceride, HDL-cholesterol, fasting plasma glucose, HbAlc, adiponectin, and hsCRP (Table 1). Urinary concentration of 8-epi-PGF2a was significantly higher in subjects diagnosed with MetS (either definition) than in those without (Table 1, Fig 1a). There was no difference between male and female subjects 
Table 2 Correlation Coefficients of the Relationships Between Urinary 8-epi-PGF2a Concentration and Various Parameters of the MetS

\begin{tabular}{lcc}
\hline \hline & $r$ & $p$ value \\
\hline Age & 0.228 & 0.0193 \\
BMI & 0.585 & $<0.0001$ \\
Waist circumference & 0.559 & $<0.0001$ \\
VFA & 0.636 & $<0.0001$ \\
SFA & 0.493 & $<0.0001$ \\
Systolic blood pressure & 0.327 & 0.0006 \\
Diastolic blood pressure & 0.118 & $N S$ \\
Total cholesterol & 0.181 & $N S$ \\
Triglyceride & 0.403 & $<0.0001$ \\
HDL-cholesterol & -0.198 & 0.0425 \\
Fasting plasma glucose & 0.127 & $N S$ \\
Hemoglobin Alc & 0.207 & 0.0337 \\
Adiponectin & -0.464 & $<0.0001$ \\
hsCRP & 0.529 & $<0.0001$ \\
Smoking index & 0.205 & 0.0354 \\
\hline
\end{tabular}

Smoking index is expressed as cigarettes/day $\times$ years. Abbreviations see in Table 1.

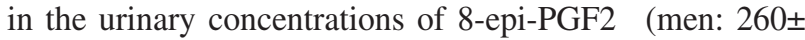
$107.7 \mathrm{pg} / \mathrm{mg} \mathrm{Cr}$; women: $260.7 \pm 147.8 \mathrm{pg} / \mathrm{mg} \mathrm{Cr}$ ).

We categorized the subjects into quartiles according to the urinary 8-epi-PGF2a concentration (category $1(\mathrm{n}=$ 25): 40.0-145.0 pg/mg Cr; category $2(\mathrm{n}=25): 150.0$ $224.0 \mathrm{pg} / \mathrm{mg} \mathrm{Cr}$; category 3 ( $\mathrm{n}=28): 231.0-331.0 \mathrm{pg} / \mathrm{mg} \mathrm{Cr}$; category $4(\mathrm{n}=27): 332.0-710.7 \mathrm{pg} / \mathrm{mg} \mathrm{Cr})$. The prevalence of MetS (both definitions) significantly increased with increased 8-epi-PGF2a urinary concentration (Japanese criteria: $p=0.0014$; AHA/NHLBI criteria: $p=0.0018$, MannWhitney U-test) (Fig 1b). Furthermore, the number of components of the MetS (abdominal obesity, hypertriglyceridemia, low HDL-cholesterol, hypertension, and high fasting glucose) significantly increased with increased 8epi-PGF2a urinary concentration (Fig 1c). We further investigated the relationship between urinary 8-epi-PGF2a concentration and selected conditions associated with MetS and the coefficients are listed in Table 2.

Urinary 8-epi-PGF2a concentration correlated positively with age, and of the anthropometric parameters, there was a significant correlation with BMI, WC, VFA, and SFA. Urinary 8-epi-PGF2a concentration correlated positively with systolic blood pressure, HbAlc, triglycerides, and smoking index and negatively with HDL-cholesterol, but not with fasting plasma glucose, diastolic blood pressure, or total cholesterol. Plasma adiponectin and hsCRP concentrations correlated significantly with urinary 8-epi-PGF2a concentration. The coefficient for the correlation of VFA with urinary 8-epi-PGF2a concentration was the highest among all parameters analyzed $(r=0.636, p<0.0001$, Table 2$)$. Furthermore, among non-obese subjects, the correlation a

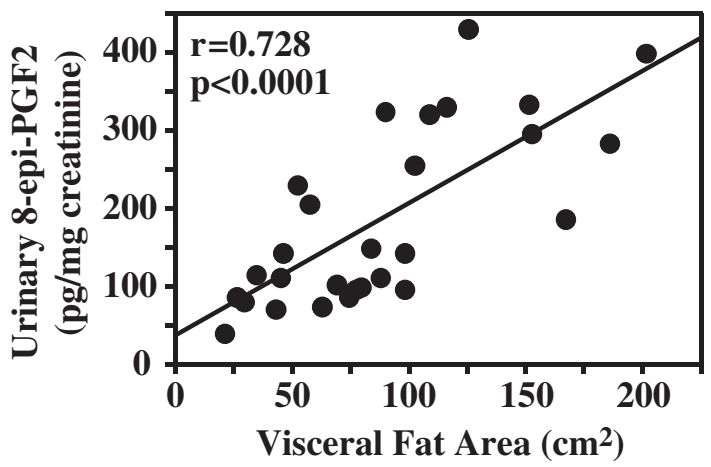

b

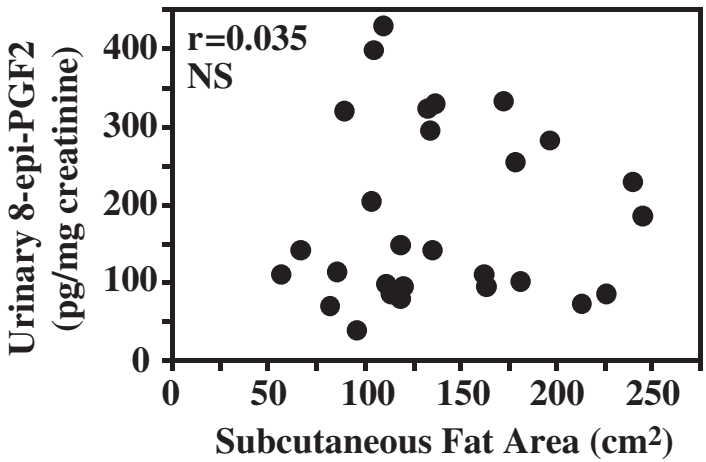

C

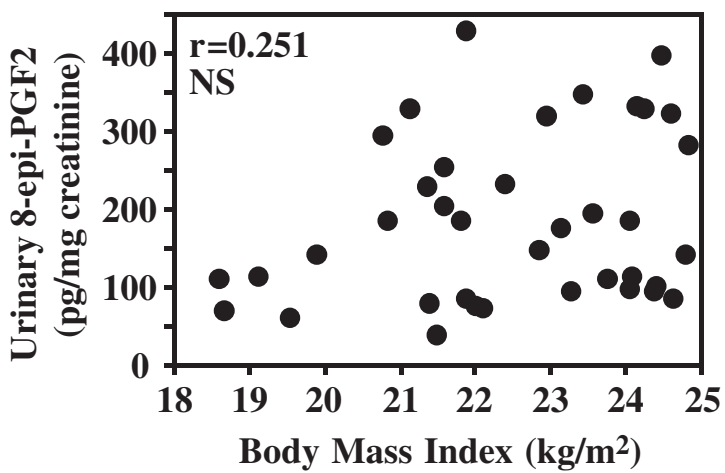

Fig 2. Association of urinary 8-epi-prostaglandin F2a (8-epi-PGF2a) concentration with visceral fat area, subcutaneous fat area or body mass index (BMI) in the non-obese subjects (BMI $<25, n=38$ ). (a) Correlation between urinary 8-epi-PGF2a concentration and visceral fat area. (b) Association of urinary 8-epi-PGF2a concentration with subcutaneous fat area. (c) Association of urinary 8-epi-PGF2a concentration with BMI. NS, not significant.

Table 3 Stepwise Multiple Regression With Urinary 8-epi-PGF2a Concentration as the Dependent Variable

\begin{tabular}{ccccc}
\hline \hline Independent variable & Regression coefficient & Standard error & Standardized regression coefficient & $p$ value \\
\hline VFA & 0.779 & 0.176 & 0.467 & $<0.0001$ \\
Adiponectin & -170.914 & 72.091 & -0.238 & 0.0212 \\
hsCRP & 57.866 & 27.012 & 0.223 & 0.0365 \\
Intercept & 296.788 & 65.849 & & $<0.0001$ \\
\hline
\end{tabular}

Adjusted $R^{2}: 0.520$

Not accepted variables (F value $<4.0)$ were age, systolic blood pressure, hemoglobin Alc, triglyceride, HDL-cholesterol, and smoking index.

Abbreviations see in Table 1. 
coefficient of VFA with urinary 8-epi-PGF2a concentration was higher (VFA: $r=0.728, p<0.0001$, Fig 2a) than that in all subjects $(\mathrm{r}=0.636$, Table 2$)$. There was no significant correlation between SFA or BMI and urinary 8-epi-PGF2a concentration in non-obese subjects (SFA: $r=0.035$, not significant (NS), Fig 2b; BMI: r=0.251, NS, Fig 2c).

To examine if the positive correlation between VFA and urinary 8-epi-PGF2a concentration was independent of other clinical factors associated with MetS, including age, smoking index, systolic blood pressure, HbA1c, triglyceride, HDL-cholesterol, hsCRP, and adiponectin, stepwise multiple regression analyses were performed. As shown in Table 3, VFA was the strongest and independent determinant of urinary 8-epi-PGF2a concentration $(\mathrm{p}<0.0001)$ followed by adiponectin $(\mathrm{p}=0.0212)$ and hsCRP $(\mathrm{p}=0.0365)$.

\section{Discussion}

The major findings of the present cross-sectional study indicate that the systemic oxidative stress increased in the subjects with MetS, and was strongly correlated with visceral fat accumulation.

Plasma levels of adipocytokines are dysregulated in visceral fat accumulation, including inflammatory adipocytokines, such as interleukin-6, TNFa, and CRP, and this chronic low-grade inflammation in MetS is involved in the pathogenesis of atherosclerotic cardiovascular diseases. $42-45$ Hypoadiponectinemia is also located upstream of the pathogenesis of metabolic diseases and atherosclerosis ${ }^{23-25}$ However, the precise molecular mechanism of adipocytokine dysregulation has not been fully elucidated. Using animal models, we recently reported that plasma $\mathrm{H}_{2} \mathrm{O}_{2}$, a hazardous ROS, is already augmented in the obese and nondiabetic state, and that increased levels of ROS primarily originate from accumulated fat, not from liver, muscle or aorta 31 That same study also demonstrated that increased ROS in obesity caused dysregulation of adipocytokine production, including decreased adiponectin and increased PAI-1 and TNFa, and that treatment with antioxidants in vivo redressed the adipocytokine dysregulation, resulting in improvement of glucose intolerance, hypertriglyceridemia, and fatty liver in obese mice ${ }^{31}$ These findings suggest that increased fat ROS in obesity is a candidate upstream factor for adipocytokine dysregulation leading to MetS.

The Framingham study revealed that BMI was highly associated with systemic oxidative stress. ${ }^{46}$ However, whether ROS are linked more to visceral or to subcutaneous fat accumulation is still unknown. In the present study, we measured VFA and SFA by the CT cross-sectional method 33 The urinary 8-epi-PGF2a concentration was more strongly associated with visceral fat accumulation than with subcutaneous fat in all subjects enrolled in this study (Table 2). In the non-obese subjects, VFA was more significantly correlated with urinary 8-epi-PGF2a than in all subjects, although there was no significant correlation between SFA or BMI and urinary 8-epi-PGF2a concentration (Fig2). Moreover, stepwise multiple regression analysis indicated that visceral fat accumulation was an independent indicator of systemic oxidative stress, whereas glucose intolerance, hypertension, dyslipidemia, or aging was not. Thus, these results suggest that systemic oxidative stress, represented by the urinary 8-epi-PGF2a concentration, is strongly associated with visceral fat accumulation leading to MetS. Very recently, it was reported that there was no increase in the urinary 8-epi-PGF2a concentration in otherwise healthy 63-year-old men in Sweden with MetS,7 which might be explained by the age of the subjects. The average age of the subjects in that study was almost 10 years older than that in the present study. Further investigation is required to verify an age-related association between systemic oxidative stress and MetS.

Smoking has been reported to be associated with systemic oxidative stress, ${ }^{46,48,49}$ and in the present study, the urinary 8 -epi-PGF2a concentration of smokers $(n=15)$ was higher than that of non-smokers $(n=90)(p=0.0640)$, and the smoking index (cigarettes/day $\times$ years) significantly correlated with urinary 8-epi-PGF2a concentration ( $\mathrm{r}=0.205, \mathrm{p}=$ 0.0354 ) as shown in Table2. The smoking index was not found to be an independent determinant of urinary 8-epiPGF2a concentration in the present study, which may be related to the small number of smokers enrolled in this study. Among the non-smokers only, VFA was also the strongest and independent determinant of urinary 8-epiPGF2a concentration (data not shown).

\section{Study Limitations}

First, this is a cross-sectional study of a limited number of subjects. Second, the study group comprised Japanese men and women who visited hospital for a health checkup, including participants coming by self-referral or by recommendation from local center screening. Therefore, the subjects included a higher ratio of subjects diagnosed with MetS as compared to the general populations0

\section{Conclusion}

We have demonstrated that systemic oxidative stress, measured by urinary 8-epi-PGF2a concentration, is closely associated with visceral fat accumulation and MetS. It is important to investigate in a future prospective study whether a reduction of visceral fat by life-style intervention is associated with decreased systemic oxidative stress. It is suggested that oxidative stress, especially fat ROS, could be an important therapeutic target for future intervention strategies for visceral fat accumulation and MetS.

\section{Acknowledgments}

We thank Dr Sachiko St Jeor for the critical reading of the manuscript. We thank Shigeo Takahashi, Koji Ohashi and all members of the Funahashi Adiposcience Laboratory for the helpful discussion and comments. This work was supported in part by Grants-in-Aid for Scientific Research (B) no. 17390271 (to T.F.), Health and Labor Science Research Grants (to I.S. and T.F.), Grants-in-Aid for Scientific Research on Priority Area no. 15081209 (to I.S.), the Japanese Society of the promotion of Science no. 11770645 and 14571103 (to M.S.), the Research Fellowships of the Japan Society for the promotion of Science for Young Scientists no. 9340 (to H.N.), the Research Grant for Longevity Sciences (15-8) from the Ministry of Health, Labor and Welfare, Yamanouchi Foundation for Research on Metabolic Disorders (to H.N.), Takeda Science Foundation (to H.N., T.F. and M.S.), Suzuken Memorial Foundation (to H.N.), Senri Life Science Foundation (to H.N.), The Mochida Memorial Foundation for Medical and Pharmaceutical Research (to H.N.), and Smoking Research Foundation (to I.S. and T.F.).

\section{References}

1. Eckel RH, Grundy SM, Zimmet PZ. The metabolic syndrome. Lancet 2005; 365: $1415-1428$.

2. Isomaa B, Almgren P, Tuomi T, Forsen B, Lahti K, Nissen M, et al. Cardiovascular morbidity and mortality associated with the metabolic syndrome. Diabetes Care 2001; 24: 683-689.

3. Montague CT, O'Rahilly S. The perils of portliness: Causes and consequences of visceral adiposity. Diabetes 2000; 49: 883-888.

4. Matsuzawa Y, Funahashi T, Nakamura T. Molecular mechanism of 
metabolic syndrome X: Contribution of adipocytokines adipocytederived bioactive substances. Ann NY Acad Sci 1999; 18: 146-154.

5. Kissebah AH, Vydelingum N, Murray R, Evans DJ, Hartz AJ, Kalkhoff RK, et al. Relation of body fat distribution to metabolic complications of obesity. J Clin Endocrinol Metab 1982; 54: 254 260.

6. Fujioka S, Matsuzawa Y, Tokunaga K, Tarui S. Contribution of intra-abdominal fat accumulation to the impairment of glucose and lipid metabolism in human obesity. Metabolism 1987; 36: 54-59.

7. Nakamura T, Tokunaga K, Shimomura I, Nishida M, Yoshida S, Kotani K, et al. Contribution of visceral fat accumulation to the development of coronary artery disease in non-obese men. Atherosclerosis 1994; 107: 239-246.

8. Nagura J, Nakagawa Y, Miyanaga M, Matsuoka K, Hayashi K, Ozasa $\mathrm{K}$, et al. Relationship between abdominal visceral fat and lacunar infarcts in Japanese men. Circ J 2004; 68: 982-987.

9. Hara M, Saikawa T, Kurokawa M, Sakata T, Yoshimatsu H. Leg fat percentage correlates negatively with coronary atherosclerosis. Circ J 2004; 68: $1173-1178$.

10. Shimomura I, Funahashi T, Takahashi M, Maeda K, Kotani K, Nakamura T, et al. Enhanced expression of PAI-1 in visceral fat: Possible contributor to vascular disease in obesity. Nat Med 1996; 2: 800-803.

11. Hotamisligil GS, Shargill NS, Spiegelman BM. Adipose expression of tumor necrosis factor-alpha: Direct role in obesity-linked insulin resistance. Science 1993; 259: 87-91.

12. Steppan CM, Bailey ST, Bhat S, Brown EJ, Banerjee RR, Wright $\mathrm{CM}$, et al. The hormone resistin links obesity to diabetes. Nature 2001; 409: 307-312

13. Friedman JM, Halaas JL. Leptin and the regulation of body weight in mammals. Nature 1998; 395: 763-770.

14. Matsuzawa Y, Funahashi T, Kihara S, Shimomura I. Adiponectin and metabolic syndrome. Arterioscler Thromb Vasc Biol 2004; 24: $29-33$.

15. Arita Y, Kihara S, Ouchi N, Takahashi M, Maeda K, Miyagawa J, et al. Paradoxical decrease of an adipose-specific protein, adiponectin, in obesity. Biochem Biophys Res Commun 1999; 257: 79-83.

16. Winkler G, Lakatos P, Salamon F, Nagy Z, Speer G, Kovacs M, et al. Elevated serum TNF-alpha level as a link between endothelial dysfunction and insulin resistance in normotensive obese patients. Diabet Med 1999; 16: 207-211.

17. Libby P. Inflammation in atherosclerosis. Nature 2002; 420: 868 874.

18. Okamoto Y, Kihara S, Ouchi N, Nishida M, Arita Y, Kumada M, et al. Adiponectin reduces atherosclerosis in apolipoprotein E-deficient mice. Circulation 2002; 106: 2767-2770.

19. Yamauchi T, Kamon J, Waki H, Imai Y, Shimozawa N, Hioki K, et al. Globular adiponectin protected ob/ob mice from diabetes and ApoE-deficient mice from atherosclerosis. J Biol Chem 2003; 278: $2461-2468$

20. Shimabukuro M, Higa N, Asahi T, Oshiro Y, Takasu N, Tagawa T, et al. Hypoadiponectinemia is closely linked to endothelial dysfunction in man. J Clin Endocrinol Metab 2003; 88: 3236-3240.

21. Maeda N, Shimomura I, Kishida K, Nishizawa H, Matsuda M, Nagaretani H, et al. Diet-induced insulin resistance in mice lacking adiponectin/ACRP30. Nat Med 2002; 8: 731-737.

22. Berg AH, Combs TP, Du X, Brownlee M, Scherer PE. The adipocytesecreted protein Acrp30 enhances hepatic insulin action. Nat Med 2001; 7: 947-953.

23. Pischon T, Girman CJ, Hotamisligil GS, Rifai N, Hu FB, Rimm EB. Plasma adiponectin levels and risk of myocardial infarction in men. JAMA 2004; 291: 1730-1737.

24. Lindsay RS, Funahashi T, Hanson RL, Matsuzawa Y, Tanaka S, Tataranni PA, et al. Adiponectin and development of type 2 diabetes in the Pima Indian population. Lancet 2002; 360: 57-58.

25. Ryo M, Nakamura T, Kihara S, Kumada M, Shibazaki S, Takahashi $\mathrm{M}$, et al. Adiponectin as a biomarker of the metabolic syndrome. Circ J 2004; 68: 975-981.

26. Griendling KK, Sorescu D, Ushio-Fukai M. NAD(P)H oxidase: Role in cardiovascular biology and disease. Circ Res 2000; 86: 494-501.

27. Fleming I, Michaelis UR, Bredenkotter D, Fisslthaler B, Dehghani F, Brandes RP, et al. Endothelium-derived hyperpolarizing factor synthase (Cytochrome P450 2C9) is a functionally significant source of reactive oxygen species in coronary arteries. Circ Res 2001 88: $44-51$.

28. Steinberg D, Lewis A. Conner Memorial Lecture: Oxidative modification of LDL and atherogenesis. Circulation 1997; 95: 1062-1071.

29. Itoh S, Umemoto S, Hiromoto M, Toma Y, Tomochika Y, Aoyagi S, et al. Importance of $\mathrm{NAD}(\mathrm{P}) \mathrm{H}$ oxidase-mediated oxidative stress and contractile type smooth muscle myosin heavy chain SM2 at the early stage of atherosclerosis. Circulation 2002; 105: 2288-2295.

30. Morita H, Saito Y, Ohashi N, Yoshikawa M, Katoh M, Ashida T, et al. Fluvastatin ameliorates the hyperhomocysteinemia-induced endothelial dysfunction: The antioxidative properties of fluvastatin. Circ J 2005; 69: 475-480.

31. Furukawa S, Fujita T, Shimabukuro M, Iwaki M, Yamada Y, Nakajima Y, et al. Increased oxidative stress in obesity and its impact on metabolic syndrome. J Clin Invest 2004; 114: 1752-1761.

32. Tokunaga K, Matsuzawa Y, Ishikawa K, Tarui S. A novel technique for the determination of body fat by computed tomography. Int $J$ Obes 1983; 7: 437-445.

33. Yoshizumi T, Nakamura T, Yamane M, Islam AH, Menju M, Yamasaki K, et al. Abdominal fat: Standardized technique for measurement at CT. Radiology 1999; 211: 283-286.

34. Cracowski JL, Durand T, Bessard G. Isoprostanes as a biomarker of lipid peroxidation in humans: Physiology, pharmacology and clinical implications. Trends Pharmacol Sci 2002; 23: 360-366.

35. Shimabukuro M, Higa N, Asahi T, Oshiro Y, Takasu N. Fluvastatin improves endothelial dysfunction in overweight postmenopausal women through small dense low-density lipoprotein reduction. Metabolism 2004; 53:733-739.

36. Wang Z, Ciabattoni G, Creminon C, Lawson J, Fitzgerald GA, Patrono C, et al. Immunological characterization of urinary 8-epiprostaglandin F2 alpha excretion in man. J Pharmacol Exp Ther 1995; 275: $94-100$.

37. Committee for Japanese Definition of Metabolic Syndrome. Definition and criteria of metabolic syndrome. J Jpn Soc Intern Med 2005; 94: 794-809 (in Japanese).

38. Grundy SM, Cleeman JI, Daniels SR, Donato KA, Eckel RH, Franklin BA, et al. Diagnosis and management of the metabolic syndrome: An American Heart Association/National Heart, Lung, and Blood Institute Scientific Statement. Circulation 2005; 112: $2735-2752$.

39. The IDF consensus worldwide definition of the metabolic syndrome. Available at: http://www.idf.org/webdata/docs/IDF_Metasyndrome_ definition.pdf [accessed 16 Oct 2005].

40. Alberti KG, Zimmet P, Shaw J; IDF Epidemiology Task Force Consensus Group. The metabolic syndrome: A new worldwide definition. Lancet 2005; 366: 1059-1062.

41. Japan Society for the Study of Obesity: The Examination Committee of Criteria for 'Obesity Disease' in Japan. New criteria for 'obesity disease' in Japan. Circ J 2002; 66: 987-992.

42. Ridker PM, Buring JE, Cook NR, Rifai N. C-reactive protein, the metabolic syndrome, and risk of incident cardiovascular events: An 8-year follow-up of 14719 initially healthy American women. Circulation 2003; 107: 391-397.

43. Ridker PM, Hennekens CH, Buring JE, Rifai N. C-reactive protein and other markers of inflammation in the prediction of cardiovascular disease in women. $N$ Engl J Med 2000; 342: 836-843.

44. Yudkin JS, Kumari M, Humphries SE, Mohamed-Ali V. Inflammation, obesity, stress and coronary heart disease: Is interleukin- 6 the link? Atherosclerosis 2000; 148: 209-214.

45. Kondo N, Nomura M, Nakaya Y, Ito S, Ohguro T. Association of inflammatory marker and highly sensitive C-reactive protein with aerobic exercise capacity, maximum oxygen uptake and insulin resistance in healthy middle-aged volunteers. Circ J 2005; 69: 452 457.

46. Keaney JF Jr, Larson MG, Vasan RS, Wilson PW, Lipinska I, Corey $\mathrm{D}$, et al. Obesity and systemic oxidative stress: Clinical correlates of oxidative stress in the Framingham Study. Arterioscler Thromb Vasc Biol 2003; 23: 434-439.

47. Sjogren P, Basu S, Rosell M, Silveira A, de Faire U, Vessby B, et al. Measures of oxidized low-density lipoprotein and oxidative stress are not related and not elevated in otherwise healthy men with the metabolic syndrome. Arterioscler Thromb Vasc Biol 2005; 25: 2580 2586.

48. Morrow JD, Frei B, Longmire AW, Gaziano JM, Lynch SM, Shyr Y, et al. Increase in circulating products of lipid peroxidation (F2isoprostanes) in smokers: Smoking as a cause of oxidative damage. N Engl J Med 1995; 332: 1198-1203.

49. Tanriverdi H, Evrengul H, Kuru O, Tanriverdi S, Seleci D, Enli Y, et al. Cigarette smoking induced oxidative stress may impair endothelial function and coronary blood flow in angiographically normal coronary arteries. Circ J 2006; 70: 593-599.

50. Tanaka H, Shimabukuro T, Shimabukuro M. High prevalence of metabolic syndrome among men in Okinawa. $J$ Atheroscler Thromb 2005; 12: 284-288. 